\title{
The Concept of Frailty in Geriatric Chronic Kidney Disease (CKD) Patients
}

\author{
Morgan Lam ${ }^{a}$ Sarbjit V. Jassal ${ }^{b}$

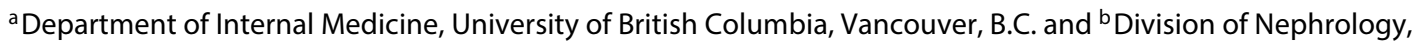 \\ University Health Network, Toronto, Ont., Canada
}

\section{Key Words}

Frailty · Geriatric · Chronic kidney disease (CKD) · End-stage renal disease $(E S R D) \cdot$ Resilience $\cdot$ Dialysis initiation

\begin{abstract}
Frailty, which is a geriatric syndrome characterized by weakness, impaired mobility, balance, and minimal reserve, is highly prevalent in the renal population. While distinct from disability and comorbidity, some of the simplest and most clinically useful scales incorporate both the burden of medical symptoms and the effect on functional independence into the evaluation of frailty. In the renal population, the frailty phenotype has been shown to correlate with important outcomes such as hospitalization and survival. Further work is required to establish if the presence of, and the treatments used for renal disease, promote the sick role and decreased participation in exercise with overestimation of frailty or if the frailty phenotype identifies people who may benefit from rehabilitation and other interventions.
\end{abstract}

C 2015 S. Karger AG, Basel

\section{Introduction}

As we enter an era where health care is largely directed at older patients with complex multi-morbidity [1], the emerging question is whether it is possible, and appropri- ate, to stratify patients, based on the concept of frailty, into programs offering treatment plans with different degrees of intervention. Initially conceived as an isolated geriatric syndrome characterized by weakness, impaired mobility, balance, and minimal reserve [2], the term frailty has evolved into a multidimensional construct with both phenotypic features as well as a biological syndrome reflecting increased vulnerability to numerous adverse events. Frailty is increasingly recognized as a geriatric syndrome that is highly prevalent, yet specifically distinct from disability and comorbidity, which previously have served as synonymous terms [3]. Simply put, frailty has emerged as a concept that can be distilled down to the notion of a biological age and shown to correlate with outcomes, independent of chronological age, gender, and comorbidities [4].

Although much of the early work that defined frailty as a syndrome excluded chronic kidney disease (CKD) as an identifiable comorbid condition $[3,5]$, there have been more recent efforts that delve into this relationship as it relates to modalities of dialytic and nondialytic care [6-9]. In fact, elderly patients with chronic kidney disease have a higher prevalence of frailty compared to those with normal renal function $[10,11]$ and the identification of frail patients is an important facet of clinical evaluation as it pertains to treatments and their effect on personal independence, survival, and overall quality of life.

\section{KARGER 125}

C 2015 S. Karger AG, Base

0253-5068/15/0393-0050\$39.50/0 


\section{Frailty as a Construct}

Early definitions of frailty were centered around the idea of irreversible age-related deterioration. Buchner and Wagner [2] first proposed that declines in neurological processes, musculoskeletal functioning, and energy metabolism were the cause of frailty, resulting in a syndrome of impaired mobility and balance, weakness, and minimal reserve. Frailty, at that time, was largely used synonymously to refer to elderly people with multiple minor problems, which collectively caused poor well-being. It was thought of as a wasting syndrome with a physiological state of vulnerability to increased morbidity and mortality $[2,3]$. Despite this, frailty is not tantamount to either comorbidity or disability; rather, comorbidity is an etiologic risk factor for frailty, and disability is an outcome of this condition [3]. That is, frailty causes disability independent of clinical and sub-clinical disease states [3]. Conversely, comorbidities can incur vulnerability and some chronic diseases are associated with very high frailty levels [10].

The prevalence of frailty increases with chronological age, as older persons tend to develop several age-related chronic conditions that interact with, and contribute to, frailty $[12,13]$. There are two distinct, but conceptually overlapping models on which the concept of frailty has been based. These are intended to aid in the identification of vulnerable, older people, at high risk of adverse outcomes including falls, worsening disability, institutionalization, and death [14].

\section{Phenotypic Model}

In the phenotypic model, frailty is described by the presenting clinical features. There have been many suggestions as to how best to define the frailty 'phenotype.' Each classification has unique strengths and weaknesses, and the multiplicity of scales perhaps reflects more the uncertainty about the term and its components.

One of the most familiar methods is one that is derived by Fried et al. from a large cohort of community-living individuals aged 65 years and older [3]. Five key characteristics, unintentional weight loss, weak grip-strength, self-reported exhaustion, slow gait speed, and low-energy expenditure, were identified as key factors. Individuals with three or more of the five factors were defined as 'frail,' while those individuals with none were 'robust.' Frail individuals were found to have increased risk of falls, functional disability, and hospitalization, and also experienced increased mortality compared to 'robust' individuals [3]. Furthermore, the intermediate ('pre-frail') group, with 1-2 factors, had outcomes intermediate between the two groups. Of
Table 1. Canadian study of health and aging 7-point clinical frailty scale (adapted from Rockwood et al. [16])

\begin{tabular}{|c|c|c|}
\hline 1 & Very fit & $\begin{array}{l}\text { Robust, active, energetic, well-motivated and } \\
\text { fit. Individuals commonly exercise regularly } \\
\text { and are in the most fit group for their age. }\end{array}$ \\
\hline 2 & Well & $\begin{array}{l}\text { No active disease symptoms but less fit than } \\
\text { in category } 1 \text {. Will exercise or are very active } \\
\text { occasionally, for example, seasonally. }\end{array}$ \\
\hline 3 & $\begin{array}{l}\text { Well with } \\
\text { treated } \\
\text { disease }\end{array}$ & $\begin{array}{l}\text { Medical problems are well controlled. } \\
\text { Often are not active beyond routine walking. }\end{array}$ \\
\hline 4 & Vulnerable & $\begin{array}{l}\text { Not frankly dependent, but these people } \\
\text { complain of being slowed up or tired. They } \\
\text { experience symptoms from their disease that } \\
\text { limit their activities. }\end{array}$ \\
\hline 5 & Mildly frail & $\begin{array}{l}\text { Individuals who have more evident slowing } \\
\text { up. They may experience limited dependence } \\
\text { on others for high-order instrumental } \\
\text { activities of daily living, for example, heavy } \\
\text { housework, finances or transportation, } \\
\text { walking outside. Progressively these } \\
\text { individuals require more assistance with } \\
\text { shopping, meal preparation, and housework. }\end{array}$ \\
\hline 6 & $\begin{array}{l}\text { Moderately } \\
\text { frail }\end{array}$ & $\begin{array}{l}\text { Help is needed with all activities outside the } \\
\text { home, and with keeping house. Inside they } \\
\text { need help with some basic activities of daily } \\
\text { living such as bathing or cueing while } \\
\text { dressing, etc. }\end{array}$ \\
\hline 7 & Severely frail & $\begin{array}{l}\text { Completely dependent on others for the } \\
\text { activities of daily living regardless of causes } \\
\text { (physical or cognitive). Sometimes classified } \\
\text { into those who are severely frail but not } \\
\text { terminally ill and those who are very severely } \\
\text { frail and highly likely to die within } 6 \text { months. }\end{array}$ \\
\hline
\end{tabular}

all five factors, low gait speed was the strongest predictor of chronic disability, long-term nursing home stays, and injurious falls [15]. One of the simplest, and possibly more clinically applicable, frailty scores is the Rockwood Clinical Frailty Scale (table 1) [16]. In this scale, a significant degree of emphasis is placed on the inability to perform ordinary activities in the home, or for personal care as well as the symptom burden. Although scoring is based purely on clinician judgment, the predictive abilities are similar to those seen with other frailty assessments.

In contrast, the Frailty Index is a score based upon the total number of deficits from a list of 70 components of health [4] - interestingly the list excludes renal disease! At all values of the Frailty Index, the degree of frailty was found to be related to survival [13]. The relationship was 
maintained across all ages, suggesting that frailty is not limited to an elderly population but, in reality, may describe a 'biological age' model.

\section{Pathophysiological Model of Cumulative Deficits}

From a more organic standpoint, frailty can be thought of as a process that results from the temporal accumulation of minor molecular-level injuries. These injuries can be genetic, environmental, or chance effects [17]; however, they accumulate over time. In the initial stages, each injury causes little clinical effect due to the physiological redundancy within the human system. Eventually, however, these deficits begin to manifest as diminished resilience, which in turn, leads to reduced adaptability and impaired homeostasis. Taken together, the effects of even minor illnesses, such as a common cold, lead to maladaptive processes leaving the body vulnerable to any new external or internal stressor [18]. Advances in biological and molecular research have shown that metabolic changes are seen in blood clotting and hormonal levels, with elevated cytokine levels, immunomodulatory abnormalities, and markers of chronic inflammation being common [12, 19-21].

\section{Other Factors Affecting Frailty}

Additional nonbiological risk factors, such as 'social vulnerability,' have recently been recognized as having a relationship with frailty [14] and higher mortality. Attributes include social support and engagement, a sense of mastery or control over one's life circumstances, and socioeconomic status. Individuals with annual incomes of $\$ 50,000$ or higher appear to have lower risks of mortality than those with lower incomes [22].

Moreover, where the current mainstream models of frailty fall short, is understanding the role of an intrinsic, or motivational factor. Cognition and mood have rarely been included in the frailty phenotype, despite their association with functional decline and disability [23]. One may speculate as to importance: a patient unmotivated to perform a task is different from the one who wants to push on, but simply cannot.

\section{Frailty and Renal Disease}

Early studies that defined frailty as a syndrome often excluded CKD from their list of comorbid condition. More recently, however, several studies have found the prevalence of frailty in patients with CKD or end-stage renal disease (ESRD) to be up to three times higher than those with normal renal function [10, 24]. In the Dialysis
Morbidity and Mortality Wave 2 study, two-thirds of the total cohort of 2275 incident dialysis patients of all ages met composite criteria for frailty [11]. Although older age had a clear relationship with the prevalence of frailty, a significant proportion of younger patients were also frail. Of interest, patients who were maintained on peritoneal dialysis had marginally lower prevalence rates [11]. In another cohort of CKD patients not requiring dialysis, the prevalence of the frailty phenotype was two-fold higher than the reference population [3] despite being, on average, 15 years younger [24].

The high prevalence of frailty is believed to be associated with disease-associated conditions such as proteinenergy wasting, anemia, inflammation, acidosis, and hormonal disturbances, among others, that may predispose them to the state of frailty [25]. In fact, CKD has long been thought of as a state of accelerated metabolic aging, as evidenced by chronic inflammation, accumulation of advanced glycation end products and oxidative stress, insulin resistance, vascular calcification, and osteoporosis [26-28]. Moreover, CKD and ESRD are associated with many of the same clinical manifestations found in older individuals without kidney disease including inactivity, loss of muscle mass, co-morbid conditions, and decline in physical and cognitive functioning [11]. Given that many of these physiologic perturbations are also associated with frailty in older people [19-21], it is not surprising that the prevalence of frailty increases as GFR, a surrogate marker of disease severity, declines - a phenomenon that is not rare, even among younger individuals [24].

Interestingly, in the CKD population, the frailty phenotype has been coupled with higher BMI and obesity rates [24]. In one series, $35 \%$ of patients reported exercising less than once per week, with correspondingly high rates of exhaustion and slowing. From these data it is tempting to speculate that the renal disease leads to increased frailty, but unclear if the presence of renal disease, and in particular its management, promotes the sick role and decreased participation in exercise with overestimation of frailty. One small study does suggest that frailty rates in large, database series may be an overestimate, although further data and understanding is required [29].

\section{The Relationship Between Frailty, Disability, and Mortality}

Although frailty increases exponentially with advanced age and with increased disability, neither old age nor disability alone identifies those at the highest risk of
Lam/Jassal 
adverse outcomes $[3,13,22]$. Those who meet criteria for frailty at baseline, have a significantly higher risk of mortality compared to non-frail individuals at both 3 -year (adjusted HR 1.49, CI 1.11-1.99) and 7-year (adjusted HR 1.63, CI 1.27-2.08) time periods [3].

Acute illness or injury, particularly those leading to hospitalization or restricted activity is strongly associated with the development of disability in ADLs [30]. This is particularly striking in a frail population where the median time to admission to an institution has been shown to be significantly shorter (34 months compared to 61 months for the frail and robust populations respectively) [13]. In a prospective cohort study of 754 non-ADL-disabled persons aged 70 or older, participants who were physically frail, defined by a single criteria of slow gait speed, were more likely than those who were not physically frail to develop disability in essential ADLs [30]. As a result, health care resource utilization is higher, and the chances of recovery reduced with higher levels of frailty [13].

\section{Potential Interventions}

The construct of frailty would be without clinical utility unless it could be used to help guide interventions and stratify patients into those who will derive benefit, no benefit, or harm from any given intervention. To date, there are no simple one-step interventions that reverse frailty. Multidisciplinary care, nutritional supplementation, and exercise may attenuate the morbidity associated with frailty, particularly when applied early $[10,14]$. In the renal population little work has been done to confirm the effectiveness, or clinical utility, of any of these interventions.

The use of frailty indices to stratify patients into different treatment strategies is perhaps where the main advantage lies. This is widely accepted in several areas of medicine already, not least in the cancer literature where treatment strategies incorporate physical performance measures and other markers of frailty. Recent data from the hypertension literature suggests that tight blood pressure control is less effective in those with frailty characteristics and suggests that targets be likewise adjusted $[31,32]$.

With respect to the ESRD population, it is tempting to use frailty characteristics to determine if patients are best managed with non-dialysis renal care or with dialysis therapies. Although frailty is associated with adverse outcomes among incident dialysis patients, including higher risk of hospitalization and death, there is little data to support the hope that frailty improves upon initiation of dialysis $[8,9]$ and, rather the opposite, a higher trend toward increasing dependence in ADLs [7]. However, it remains to be seen if it is valid or appropriate to restrict the use of dialysis in those who are deemed to be frail. Perhaps the main benefit of recognizing the frailty phenotype may lie in customized treatments that personalize targets and goals of care [33, 34].

\section{Conclusions}

Frailty is emerging as a conceptual model that is allowing health care provision to move away from organ- and disease-based approaches toward an integrated holistic model. While attractive, and likely useful as a clinical tool, some caution is warranted. Recent frailty models are dependent on characteristics such as low rates of exercise, fatigue, and poor physical function, but ignore key nonbiological factors such as intrinsic motivation and social vulnerability. At present, it remains prudent to incorporate comprehensive geriatric assessments not only before renal replacement therapy is started but also on a longitudinal basis in order to emphasize quality of life.

\section{References}

$\checkmark 1$ Hubbard RE, O’Mahony MS, Cross E, Morgan A, Hortop H, Morse RE, et al: The ageing of the population: implications for multidisciplinary care in hospital. Age Ageing 2004; 33:479-482.

$\checkmark 2$ Buchner DM, Wagner EH: Preventing frail health. Clin Geriatr Med 1992;8:1-17.

- 3 Fried LP, Tangen CM, Walston J, Newman $A B$, Hirsch $C$, Gottdiener J, et al: Frailty in older adults: evidence for a phenotype. J Gerontol A Biol Sci Med Sci 2001;56:M146M156.

Concept of Frailty in Geriatric CKD

Patients
4 Clegg A, Young J, Iliffe S, Rikkert MO, Rockwood K: Frailty in elderly people. Lancet 2013; 381:752-762.

5 Jarrett PG, Rockwood K, Carver D, Stolee P, Cosway S: Illness presentation in elderly patients. Arch Intern Med 1995;155:10601064.

6 Arnold RM, Zeidel ML: Dialysis in frail elders - a role for palliative care. N Engl J Med 2009;361:1597-1598.

7 Johansen KL, Delgado C, Bao Y, Kurella Tamura M: Frailty and dialysis initiation. Semin Dial 2013;26:690-696.
8 Kurella Tamura M, Covinsky KE, Chertow GM, Yaffe K, Landefeld CS, McCulloch CE: Functional status of elderly adults before and after initiation of dialysis. N Engl J Med 2009; 361:1539-1547.

9 Jassal SV, Chiu E, Hladunewich M: Loss of independence in patients starting dialysis at 80 years of age or older. N Engl J Med 2009; 361:1612-1613.

10 Shlipak MG, Stehman-Breen C, Fried LF, Song $\mathrm{X}$, Siscovick D, Fried LP, et al: The presence of frailty in elderly persons with chronic renal insufficiency. Am J Kidney Dis 2004;43:861-867. 
11 Johansen KL, Chertow GM, Jin C, Kutner NG: Significance of frailty among dialysis patients. J Am Soc Nephrol 2007; 18:2960-2967.

12 Hamerman D: Toward an understanding of frailty. Ann Intern Med 1999;130:945-950.

13 Rockwood K, Song X, Mitnitski A: Changes in relative fitness and frailty across the adult lifespan: evidence from the Canadian National Population Health Survey. CMAJ 2011; 183:E487-E494.

14 McMillan GJ, Hubbard RE: Frailty in older inpatients: what physicians need to know. QJM 2012;105:1059-1065.

-15 Rothman MD, Leo-Summers L, Gill TM: Prognostic significance of potential frailty criteria. J Am Geriatr Soc 2008;56:2211-2216.

16 Rockwood K, Song X, MacKnight C, Bergman H, Hogan DB, McDowell I, et al: A global clinical measure of fitness and frailty in elderly people. CMAJ 2005;173:489-495.

17 Kirkwood TBL: Understanding the odd science of aging. Cell 2005;120:437-447.

18 Gavrilov LA, Gavrilova NS: Reliability Theory of Aging and Longevity; in Handbook of the Biology of Aging, ed 6. San Diego, CA, Academic Press, 2006.

19 Hubbard RE, Sinead O'Mahony M, Woodhouse KW: Erythropoietin and anemia in aging and frailty. J Am Geriatr Soc 2008;56: 2164-2165.
20 Walston J, McBurnie MA, Newman A, Tracy RP, Kop WJ, Hirsch CH, et al: Frailty and activation of the inflammation and coagulation systems with and without clinical comorbidities: results from the Cardiovascular Health Study. Arch Intern Med 2002;162:2333-2341.

21 Hubbard RE, Woodhouse KW: Frailty, inflammation and the elderly. Biogerontology 2010;11:635-641.

22 Fried LP, Kronmal RA, Newman AB, Bild DE, Mittelmark MB, Polak JF, et al: Risk factors for 5-year mortality in older adults: the Cardiovascular Health Study. JAMA 1998;279: 585-592.

23 Bergman H, Ferrucci L, Guralnik J, Hogan DB, Hummel S, Karunananthan S, et al: Frailty: an emerging research and clinical paradigm - issues and controversies. J Gerontol A Biol Sci Med Sci 2007;62:731-737.

24 Roshanravan B, Khatri M, Robinson-Cohen C, Levin G, Patel KV, de Boer IH, et al: A prospective study of frailty in nephrology-referred patients with CKD. Am J Kidney Dis 2012;60:912-921.

25 Kim JC, Kalantar-Zadeh K, Kopple JD: Frailty and protein-energy wasting in elderly patients with end stage kidney disease. J Am Soc Nephrol 2013;24:337-351.

26 Landau M, Kurella-Tamura M, Shlipak MG, Kanaya A, Strotmeyer E, Koster A, et al: Correlates of insulin resistance in older individuals with and without kidney disease. Nephrol Dial Transplant 2011;26:2814-2819.

27 El-Abbadi M, Giachelli CM: Mechanisms of vascular calcification. Adv Chronic Kidney Dis 2007; 14:54-66.
28 Linden E, Cai W, He JC, Xue C, Li Z, Winston $\mathrm{J}$, et al: Endothelial dysfunction in patients with chronic kidney disease results from advanced glycation end products (AGE)-mediated inhibition of endothelial nitric oxide synthase through RAGE activation. Clin J Am Soc Nephrol 2008;3:691-698.

29 Painter P, Kuskowski M: A closer look at frailty in ESRD: getting the measure right. Hemodial Int 2013;17:41-49.

30 Gill TM, Allore HG, Holford TR, Guo Z: Hospitalization, restricted activity, and the development of disability among older persons. JAMA 2004;292:2115-2124.

31 Muller M, Smulders YM, de Leeuw PW, Stehouwer CD: Treatment of hypertension in the oldest old: a critical role for frailty? Hypertension 2014;63:433-441.

32 Odden MC, Peralta CA, Haan MN, Covinsky KE: Rethinking the association of high blood pressure with mortality in elderly adults: the impact of frailty. Arch Intern Med 2012;172: 1162-1168.

33 Churchill DN, Jassal SV: Dialysis: destination or journey. J Am Soc Nephrol 2014;25:1609_ 1611.

34 Vandecasteele SJ, Kurella Tamura M: A patient-centered vision of care for ESRD: dialysis as a bridging treatment or as a final destination? J Am Soc Nephrol 2014;25:16471651. 